\title{
Polymer Nanocomposites: Synthesis and Physical Properties
}

\author{
Gleb Yu. Yurkov1,2, Alexandr S. Fionov'1,3, Oleg V. Popkov'1, \\ Igor D. Kosobudskii ${ }^{4}$, Nikolay A. Taratanov 5 and Olga V. Potemkina ${ }^{5}$ \\ ${ }^{1}$ Baikov Institute of Metallurgy and Materials Science, Russian Academy of Sciences, \\ ${ }^{2}$ Moscow Power Engineering Institute (Technical University), \\ ${ }^{3}$ Institute of Radio Engineering and Electronics, Russian Academy of Sciences, \\ ${ }^{4}$ Department of Chemistry, Saratov State Technical University, \\ ${ }^{5}$ Ivanovo Institute of State Fire Service of EMERCOM of Russia \\ $1,2,3,4,5$ Russia
}

\section{Introduction}

Development of the science of metal-containing nanoparticles, including those stabilized in polymer matrices, is stimulated by the steady growth of interest paid to this problem in many areas of chemistry, physics, and materials science (Pomogailo et al., 2004; Gubin et al., 2005, a; Gubin et al., 2005, b; Scomski, 2003; Hyeon, 2003; Lin \& Samia, 2006; Gubin et al., 2002; Ushakov et al., 2005).

As is well known, materials based on metal-containing nanoparticles are thermodynamically unstable (Gubin, 2000). Isolation within a matrix is a prospective method for stabilization of nanoparticles. Various polymers can be used for this purpose, e.g. polyethylene (Gubin et al., 2005, b; Zanetti \& Costa, 2004), polypropylene (Gubin et al., 2005, b; Zanetti et al., 2001), polytetrafluoroethylene (Korobov et al., 2004; Yurkov et al., 2006), etc. These polymers have relatively high thermal stability, unique rheologic properties, high dielectric strength, they are chemically inert and processable, which provides means for fabrication of objects of desired form and dimensions. Methods for syntheses of these polymers are well elaborated.

Most polymer materials are good dielectrics with stable physical and chemical properties (Xia et al., 2006). Chemical stability of polymers allows using them in severe conditions (Hong et al., 2003). Modification of polymers with various inorganic fillers is used for altering their mechanical, electric, and other operational properties (Brosseau et al., 2001). The intensity of these properties' change depends on the nature, composition, morphology, and concentration of filler, as well as parameters of the flow process of filler's introduction into the matrix.

Nanoscaled fillers are especially interesting for creation of composite materials based on polymer matrices, as the first have a number of properties which are not specific for bulk materials (Kawasumi et al., 1997; Wang \& Herron, 1991; Siegel, 1993; Gleiter et al., 2001; Gubin et al., 2003). Supposedly, introduction of metal-containing nanoparticles into polymers and variation of their composition, concentration, and sizes would provide means 
for controlling mechanical, electrical, magnetic, and other properties of composite nanomaterials produced this way (Gangopadhyay \& De, 2000).

Herein we present results of a few years of studies concerned with development, creation, and investigation of composite nanomaterials based on metal-containing nanoparticles embedded in the low density polyethylene (LDPE) matrix. The selection of LDPE as the stabilizing matrix was made due to the material's low cost and well-developed production technology. Besides that, LDPE can be readily mixed with both organic and inorganic fillers (Pomogailo et al., 2004; Gubin et al., 2005, b; Yurkov et al., 2006; Xia et al., 2006; Hong et al., 2003; Hong et al., 2005). LDPE is a thermoplastic polymer, which allows using it for making objects of desired form and dimensions in mild conditions. Due to the abovementioned properties, LDPE is widely used in electrical engineering and radio engineering industries. Nanoparticles containing iron, cobalt, copper, cerium oxide and semiconductor CdS were used as the fillers in the course of this work.

\section{Experimental}

The general protocol for synthesizing nanoparticles embedded in a polymer matrix is as follows. A metal-containing precursor solution is added to the rapidly stirred LDPE-oil solution-melt at $270-300^{\circ} \mathrm{C}$ (Gubin et al., 2005, b; Gubin et al., 2003). Argon is supplied to the reactor during all the synthesis for removing air and gaseous reaction products (fig. 1).

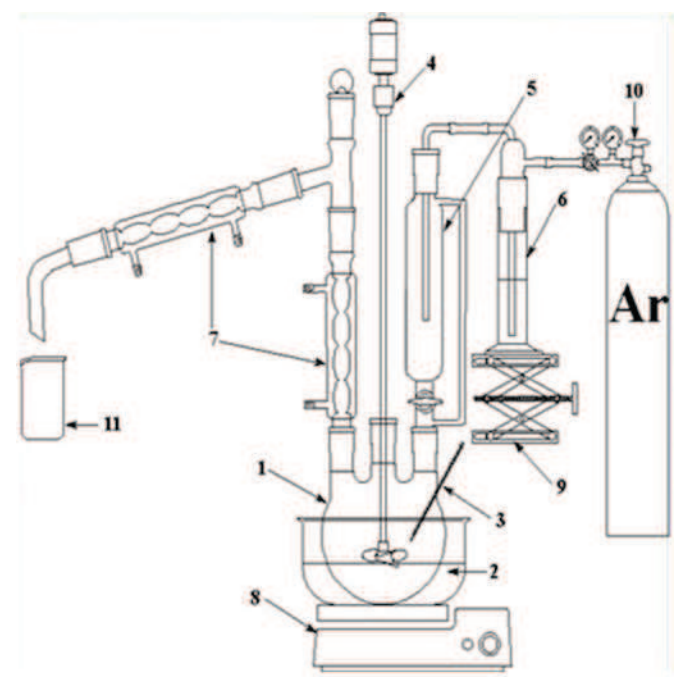

Fig. 1. Schematics of the laboratory setup for synthesis of composite materials based on metal nanoparticles and organic polymer matrices: 1 - glass reactor (3- or 4-necked flask); 2 - bath; 3 - thermometer; 4 - high-speed electric stirrer; 5 - dropping funnel with backpressure; 6 - bubbler with pyrogallol; 7 - condenser; 8 - electric heating mantle; 9 - lab jack; 10 - argon source; 11 - waste accumulation

Formates, acetates, oxalates, and carbonyls of iron and cobalt were used as the metalcontaining precursors. Copper acetate, zinc and cadmium thioacetate complexes were used for syntheses of semiconductor nanoparticles; cerium nitrate and complex compounds of 
cerium were used for syntheses of ceria nanoparticles. The synthesis of CdS nanoparticles was performed in two stages. First, $\mathrm{CdCl}_{2}$ nanoparticles were prepared in LDPE-oil solution melt via dropwise addition of an acidified cadmium chloride solution. The second stage was chemical modification of the formed cadmium chloride nanoparticles via their interaction with hydrogen sulphide. The latter was bubbled through the LDPE-oil solution-melt with cadmium-containing nanoparticles $\left(\mathrm{CdCl}_{2}\right)$ using argon as the carrier gas.

Reactions of thermal decomposition of the precursors used are listed below:

$$
\begin{gathered}
\mathrm{Fe}(\mathrm{CO})_{5} \rightarrow \mathrm{Fe}+5 \mathrm{CO} \text { (the main reaction), } \\
\mathrm{Fe}(\mathrm{CO})_{5} \rightarrow \mathrm{Fe}_{2} \mathrm{O}_{3}+\mathrm{CO}+\mathrm{C}, \\
\mathrm{Fe}(\mathrm{CO})_{5} \rightarrow \mathrm{FeO}+\mathrm{CO}+\mathrm{C}, \\
\mathrm{Fe}(\mathrm{CO})_{5} \rightarrow \mathrm{FeC}+\mathrm{CO}+\mathrm{CO}_{2} . \\
\mathrm{Fe}(\mathrm{HCOO})_{3} \rightarrow \mathrm{Fe}+\mathrm{CO}_{2} \uparrow+2 \mathrm{CO} \uparrow+\mathrm{H}_{2} \mathrm{O} . \\
\mathrm{Fe}\left(\mathrm{CH}_{3} \mathrm{COO}\right)_{3} \rightarrow \mathrm{Fe}_{2} \mathrm{O}_{3}+\mathrm{CO}_{2} \uparrow+2 \mathrm{CO} \uparrow+\mathrm{H}_{2} \mathrm{O} ; \\
\mathrm{Co}(\mathrm{HCOO})_{2} \rightarrow \mathrm{Co}+\mathrm{CO}_{2} \uparrow+2 \mathrm{CO} \uparrow+\mathrm{H}_{2} \mathrm{O} . \\
\mathrm{Co}\left(\mathrm{CH}_{3} \mathrm{COO}\right)_{2} \rightarrow \mathrm{CoO}+\mathrm{CO}_{2} \uparrow+2 \mathrm{CO} \uparrow+\mathrm{H}_{2} \mathrm{O} . \\
\mathrm{Cu}\left(\mathrm{CH}_{3} \mathrm{COO}\right)_{2} \rightarrow \mathrm{Cu}+2 \mathrm{CO}_{2}+\mathrm{H}_{2}+2 \mathrm{CH}_{2} \mathrm{O} \\
\mathrm{CdCl}_{2}+\mathrm{H}_{2} \mathrm{~S} \rightarrow \mathrm{CdS}^{2}+2 \mathrm{HCl} \uparrow \\
\mathrm{Ce}\left(\mathrm{NO}_{3}\right)_{3} \cdot 6 \mathrm{H}_{2} \mathrm{O} \rightarrow \mathrm{CeO}_{2}+\mathrm{H}_{2} \mathrm{O}+\mathrm{NO}_{2} \uparrow ; \\
\left(\mathrm{Et} \mathrm{N}_{4}\right)_{2} \mathrm{Ce}\left(\mathrm{NO}_{3}\right)_{6} \rightarrow \mathrm{CeO}{ }_{2}+\mathrm{H}_{2} \mathrm{O}+\mathrm{N}_{2} \mathrm{O} \uparrow+\mathrm{CO}_{2} \uparrow ; \\
\left(\mathrm{NH}_{4}\right)_{2} \mathrm{Ce}\left(\mathrm{NO}_{3}\right)_{6} \rightarrow \mathrm{CeO}_{2}+\mathrm{H}_{2} \mathrm{O}+\mathrm{N}_{2} \mathrm{O} \uparrow+\mathrm{O}_{2} \uparrow ;
\end{gathered}
$$

$\left[\mathrm{Me}\left(\mathrm{CH}_{3} \mathrm{COO}\right)_{2} \cdot\left(\mathrm{NH}_{2}\right)_{2} \mathrm{CS} \cdot \mathrm{H}_{2} \mathrm{O}\right] \rightarrow \mathrm{MeS}+$ thiocarbamide decomposition products

It is worthwhile to say that side reactions can take place during a synthesis, which will have effect on chemical composition of resulting nanoparticles. Besides that, nanoparticles of like composition can be prepared using different precursors.

The samples produced were separated from oil with benzene using a Soxhlet extractor and were dried in vacuum afterwards. All the samples were stored in air. The materials produced were coloured powders, with colours dependant on nanoparticles' sizes and composition.

Samples in the form of tablets were produced via hot pressing in a steel die using a hand screw press $(6 \mathrm{kN})$. The pressing temperature was selected in such a way as to transform all the powder to a plastic mass avoiding its thermal destruction. Tablets $12 \ldots 25 \mathrm{~mm}$ in diameter and $0.25 \ldots 3 \mathrm{~mm}$ thick were prepared this way.

The protocol described was used for preparation of nanocomposites based on LDPE containing nanoparticles (Kosobudsky \& Yurkov, 2000; Yurkov et al., 2001; Yurkov et al., 2002; Yurkov et al., 2007; Fionov et al., 2008, b; Taratanov et al., 2009, a; Popkov et al., 2009; 
Elkin \& Yurkov, 2009; Taratanov et al., 2009, b; Volkov et al., 2010; Yurkov et al., 2009; Taratanov et al., 2010).

Structure, composition, and physical properties of the synthesized nanocomposite materials were studied using a set of instrumental methods (transmission electronic microscopy (TEM), extended X-ray absorption fine structure (EXAFS) spectroscopy, electron paramagnetic resonance (EPR), X-ray powder diffraction (XRD), etc.). Electrophysical properties of the composites prepared are discussed below.

\section{Electrophysical properties of nanocomposites}

\subsection{Electrophysical properties of composites containing magnetic nanoparticles}

Five samples have been synthesized for conducting these studies. Samples 1 and 2 were prepared from $\mathrm{Fe}(\mathrm{CO})_{5}$ and contain different amounts of iron-containing nanoparticles embedded in low density polyethylene. The nanoparticles are comprised of three phases: metallic iron, iron oxide and carbide. Sample 3 was prepared from iron (III) formate $\mathrm{Fe}(\mathrm{HCOO})_{3}$ and contains nanoparticles which are mainly comprised of $\mathrm{Fe}_{3} \mathrm{O}_{4}$. Sample 4 was synthesized using iron (II) oxalate $\mathrm{FeC}_{2} \mathrm{O}_{4} \cdot 2 \mathrm{H}_{2} \mathrm{O}$; nanoparticles in it are comprised of iron oxide $\mathrm{Fe}_{3} \mathrm{O}_{4}$ and $\varepsilon$-Fe. Sample 5 was prepared via thermal destruction of cobalt (II) acetate and contains nanoparticles with complex structure; the nanoparticles are comprised of $\mathrm{CoO}$, $\mathrm{Co}$, and $\mathrm{Co}_{3} \mathrm{O}_{4}$ (Gudoshnikov et al., 2003; Yurkov et al., 2007, b).

Volume resistance, $\rho_{V}$, and permittivity, $\varepsilon$, values of the abovementioned samples are listed in tables 1 and 2. Figures 2, 3 depict dependencies of $\rho_{V}$ and $\varepsilon$ of the samples with Fecontaining nanoparticles as functions of concentration, $C$. The sample with $C=0$ is low density polyethylene with no filler which was subject to all operations involved in preparation of the abovementioned samples.

\begin{tabular}{|c|c|c|c|c|}
\hline \multirow{2}{*}{ Sample } & \multirow{2}{*}{ C, wt. \% } & \multicolumn{3}{|c|}{$\begin{array}{c}\rho_{V}, \Omega \cdot \mathrm{m} \\
\text { at voltage }\end{array}$} \\
\cline { 3 - 5 } & & $10 \mathrm{~V}$ & $100 \mathrm{~V}$ & $1000 \mathrm{~V}$ \\
\hline Polyethylene & 0 & - & $4.9 \cdot 10^{14} \pm 25 \%$ & $3.9 \cdot 10^{14} \pm 5 \%$ \\
\hline Sample 1 & 5 & $1.4 \cdot 10^{14} \pm 50 \%$ & $1.2 \cdot 10^{14} \pm 25 \%$ & $0.9 \cdot 10^{14} \pm 5 \%$ \\
\hline Sample 2 & 10 & $5.5 \cdot 10^{13} \pm 25 \%$ & $5.5 \cdot 10^{13} \pm 10 \%$ & $4.25 \cdot 10^{13} \pm 5 \%$ \\
\hline Sample 3 & 20 & $4.5 \cdot 10^{12} \pm 25 \%$ & $3.0 \cdot 10^{12} \pm 10 \%$ & $1.0 \cdot 10^{11} \pm 5 \%$ \\
\hline Sample 4 & 20 & $9.5 \cdot 10^{13} \pm 25 \%$ & $5.1 \cdot 10^{13} \pm 10 \%$ & $1.5 \cdot 10^{13} \pm 5 \%$ \\
\hline Sample 5 & 20 & $2.8 \cdot 10^{13} \pm 25 \%$ & $1.6 \cdot 10^{13} \pm 10 \%$ & $5.5 \cdot 10^{12} \pm 5 \%$ \\
\hline
\end{tabular}

Table 1. Volume resistance of composite nanomaterials

\begin{tabular}{|c|c|c|c|c|}
\hline Sample & C, wt. \% & $\varepsilon(1 \mathrm{kHz})$ & $\varepsilon(1 \mathrm{MHz})$ & $d, \mathrm{~nm}$ \\
\hline Polyethylene & 0 & 2.94 & 2.70 & - \\
\hline Sample 1 & 5 & 2.98 & 2.69 & 4.9 \\
\hline Sample 2 & 10 & 3.63 & 3.32 & 5.1 \\
\hline Sample 3 & 20 & 4.52 & 3.56 & 11.5 \\
\hline Sample 4 & 20 & 3.67 & 3.37 & 2.4 \\
\hline Sample 5 & 20 & 3.96 & 3.01 & 8.3 \\
\hline
\end{tabular}

Table 2. Permittivity of composite nanomaterials 


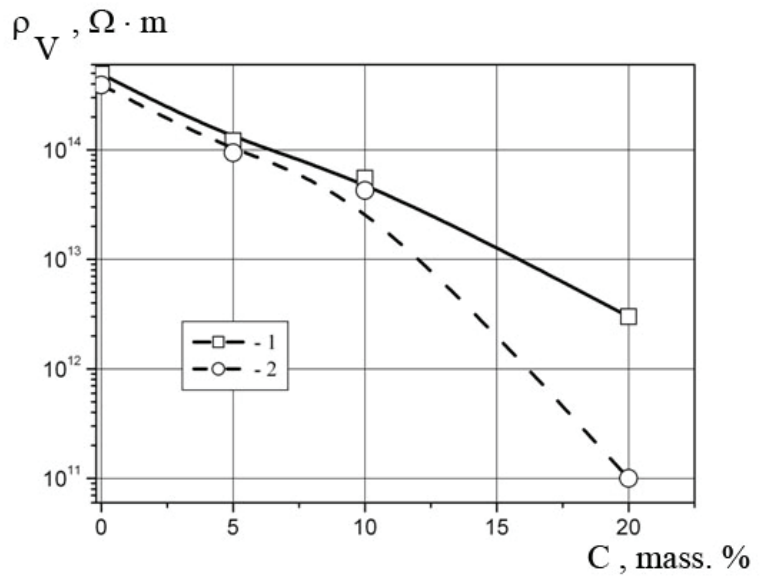

Fig. 2. Volume resistance of samples 1, 2, 3 as a function of nanoparticles weight concentration at different voltage: $1-100 \mathrm{~V} ; 2-1000 \mathrm{~V}$

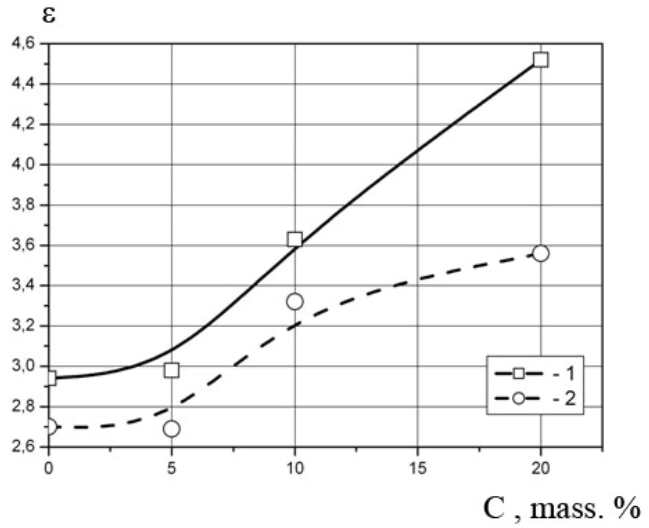

Fig. 3. Permittivity of samples 1, 2, 3 as a function of nanoparticles weight concentration at low frequencies: $1-1 \mathrm{kHz} ; 2-1 \mathrm{MHz}$

DC volume resistance of the samples $\left(10^{11}-10^{15} \Omega \mathrm{m}\right)$ steadily lowers as the filler concentration $C$ grows; the values are in the range typical for dielectrics. The lower volume resistance of the materials compared to that of the "empty" LDPE it is a result of polyethylene structure change towards higher amorphism and porosity which results in higher molecular mobility and lower ion dissociation energy in the polymer. This is also the reason for the steady growth of permittivity which occurs as the filler concentration increases.

The difference between volume resistance and permittivity values of the processed unfilled LDPE and the "normal" LDPE (1016 - $\left.10^{18} \Omega \cdot \mathrm{m}, 2.2-2.3\right)$ can be attributed to a higher amount of admixtures as a result of the treatment. 
Volume resistance of samples with 5\% and 10\% wt. nanoparticles (samples 1 and 2), as well as that of the "empty" polyethylene, weakly depends on the field applied and linearly decreases as concentration of nanoparticles increases within all the operating field strength range.

As concentration of nanoparticles reaches $20 \% \mathrm{wt}$., dependence of volume resistance as a function of applied voltage becomes more pronounced. Samples 4 and 5 have 3 times less volume resistance at $1000 \mathrm{~V}$ than at $100 \mathrm{~V}$, whereas the resistance drop of sample 3 is more than 10 times at the same voltages.

Additional contribution to admittance current can be made by polarization phenomena caused by nanoparticles' polarization: macro-shift polarization (within a sample) and microshift polarization (within some sites), as well as slowly developing dipole polarization.

Conductivity of filled LDPE depends on both composition and size of nanoparticles it contains. It is well illustrated by the lower volume resistance of sample 3 compared to that of samples 4 and 5 at $1000 \mathrm{~V}$.

The steady growth of permittivity is caused by the contribution of metal-containing nanoparticles' polarization. The nanoparticles have more loose electron shells and hence higher polarizability compared to those of the polymer matrix, which results in the growth of permittivity $\varepsilon$ as the filler concentration increases.

The difference between permittivity values of samples 3 and 4 which have equal nanoparticles concentrations is due to the higher susceptibility of larger particles.

Results of permittivity and electromagnetic radiation absorption measurements performed at microwave frequencies for samples with different filler concentrations are given in figs. 4 and 5 .

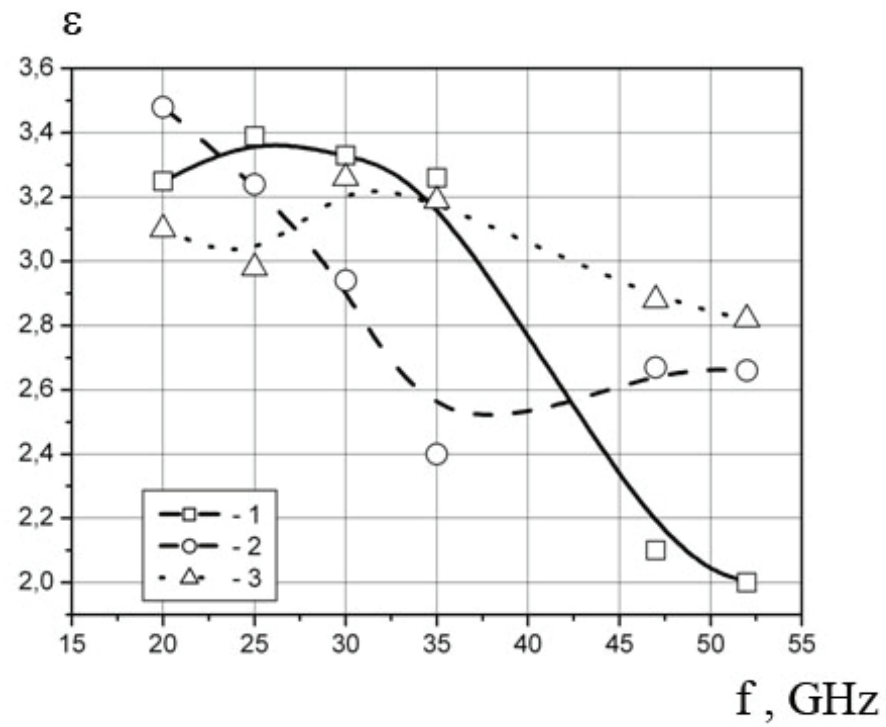

Fig. 4. Permittivity as a function of microwave radiation frequency: 1 -sample 1; 2 - sample 2; 3 - sample 3 


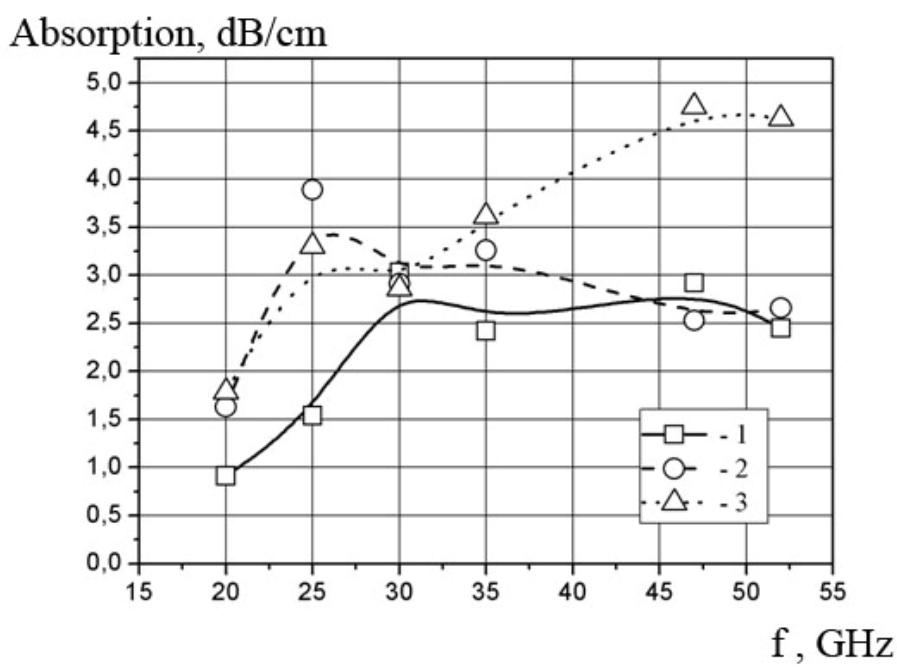

Fig. 5. Microwave absorption as a function of radiation frequency: 1 - sample 1 ; 2 - sample 2; 3 - sample 3

The data on permittivity and absorption in the microwave range can be used for estimating proportion of amplitude and time characteristics of relaxation processes. The decrease of permittivity and almost constant dielectric losses of samples 1 and 2 can be explained by decrease of relaxation processes' intensity with the relaxation rate unchanged. The increase of nanoparticles' concentration to $20 \%$ wt. (sample 3) results in decrease of relaxation time, but relaxation intensity doesn't change. There is a tendency towards increase of both dipole relaxation process intensity and rate as concentration of nanoparticles in the polymer grows. Just as in case of low frequencies, the dependencies mentioned above can be attributed to polarization of metal-containing nanoparticles whose susceptibility increases along with their size. The results of microwave measurements indicate that the samples produced have steady permittivity and absorption in a wide frequency range within the band studied.

Samples containing 30\% wt. iron- or cobalt-containing nanoparticles have low volume resistance $\left(\approx 10^{2} \Omega \mathrm{m}\right)$. Nanoparticles in these samples are relatively large $\left(d_{\mathrm{av}} \approx 8 \mathrm{~nm}\right)$ and have well-formed metallic core. Electromagnetic radiation power reflection and extinction coefficients at $30 \mathrm{GHz}$ are given in table 3 (Fionov et al., 2008, a).

\begin{tabular}{|c|c|c|c|}
\hline $\begin{array}{c}\text { Sample } \\
\text { composition }\end{array}$ & $C_{,} \%$ wt. & $K_{\text {ref }}$ & $K_{\text {ext }} \mathrm{dB} / \mathrm{cm}$ \\
\hline LDPE+Co $\mathrm{O}_{\mathrm{y}}$ & 30 & 0.10 & 77 \\
\hline LDPE+Fe $\mathrm{O}_{\mathrm{y}}$ & 30 & 0.53 & 45 \\
\hline
\end{tabular}

Table 3.

Application of such composite materials in microwave equipment as nonlinear distribution elements (fillers of waveguide ducts and resonators, thin-film coats, electromagnetic screens, etc.) would lead to creation of a number of new devices for electromagnetic signal transformation and elements of active stealth technology. 


\subsection{Study of complex magnetic and dielectric permittivity at microwave frequencies}

Samples prepared for measuring complex magnetic and dielectric permittivity at microwave frequencies using the cavity method were in the form of powders (granule size less than $300 \mu \mathrm{m})$ put in capillary vessels.

Among the materials with no more than $20 \%$ wt. nanoparticles, the one with $20 \% \mathrm{wt}$. Cocontaining nanoparticles has the highest values of $\varepsilon^{\prime} \approx 6.5, \varepsilon^{\prime \prime} \approx 0.11, \mu^{\prime} \approx 1.6$, and $\mu^{\prime \prime} \approx 4.9 \cdot 10^{-3}$ at 6.5 GHz.

Results of measurements performed for powders containing $\mathrm{Fe}_{3} \mathrm{O}_{4}$ are given in fig. 6 . Dielectric and magnetic permittivities, as well as dielectric and magnetic losses, grow as concentration of $\mathrm{Fe}_{3} \mathrm{O}_{4}$ increases. The highest values of $\varepsilon^{\prime}$ and $\mu^{\prime}$ are observed for nanocomposites with $63 \%$ wt. $\mathrm{Fe}_{3} \mathrm{O}_{4}$ at the long-wave part of the studied frequency range (25.0 and 4.5, respectively); the highest dielectric and magnetic losses are detected at 5$12 \mathrm{GHz}\left(\varepsilon^{\prime \prime} \max \approx 10\right)$ and 3-6 GHz $\left(\mu^{\prime \prime} \max \approx 2,7\right)$, respectively.

As magnetic properties $\left(\mu^{\prime}\right.$ and $\left.\mu^{\prime \prime}\right)$ of the nanocomposites are mainly determined by magnetic properties of nanoparticles, whereas dielectric properties are affected by concentrations of free and bound charges in the whole system, the unsteady behaviour of $\varepsilon^{\prime}$ and $\varepsilon^{\prime \prime}$ in case of different concentrations of metal-containing nanoparticles at different frequencies can be attributed to uncontrolled changes of composite structure.
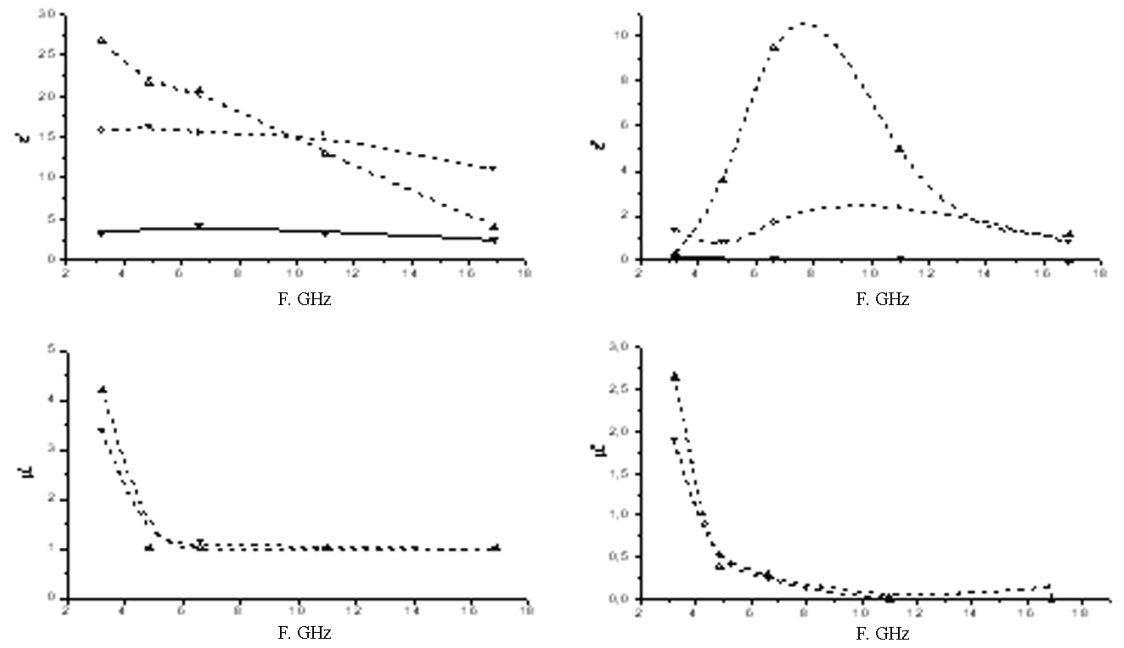

Fig. 6. Effect of $\mathrm{Fe}_{3} \mathrm{O}_{4}$ weight concentration of $\varepsilon^{*}$ and $\mu^{*}$ of a composite as functions of frequency: $\longrightarrow 20 \% \mathrm{Fe}_{3} \mathrm{O}_{4} ;--0--30 \% \mathrm{Fe}_{3} \mathrm{O}_{4} ;--\Delta--63 \% \mathrm{Fe}_{3} \mathrm{O}_{4}$

For this reason, the influence of synthesis conditions on phase composition of metalcontaining nanoparticles and electrophysical properties of composites has been investigated. Three types of materials have been studied: the initial one, annealed in inert atmosphere, and annealed in air.

Basing on Mössbauer spectra, nanoparticles in the initial sample with $63 \%$ wt. $\mathrm{Fe}_{3} \mathrm{O}_{4}$ were found to contain $11 \%$ wt. $\alpha$-Fe with $\mathrm{Fe}_{3} \mathrm{O}_{4}$ being the rest. Concentration of $\alpha$-Fe has dropped to $4 \% \mathrm{wt}$. after annealing in inert atmosphere. Nanoparticles in samples prepared by annealing in air were entirely comprised of $\gamma-\mathrm{Fe}_{2} \mathrm{O}_{3}$. 
$\mathrm{XRD}$ data revealed some ordering of nanoparticles structure after annealing, perhaps as a result of their recrystallization.

The influence of the additional thermal treatment and oxidation of the initial composite which contained $63 \%$ wt. $\mathrm{Fe}_{3} \mathrm{O}_{4}$ can be seen in fig. 7 . The treatment in inert atmosphere leads to increase of dielectric permittivity and both magnetic and dielectric losses in the composite.

The most prominent result of the additional oxidation of $\mathrm{Fe}_{3} \mathrm{O}_{4}$ nanoparticles to $\mathrm{Fe}_{2} \mathrm{O}_{3}$ is the decrease of dielectric losses and $\varepsilon^{\prime}$. Magnetic losses also decreased a bit at $3-7 \mathrm{GHz}$.
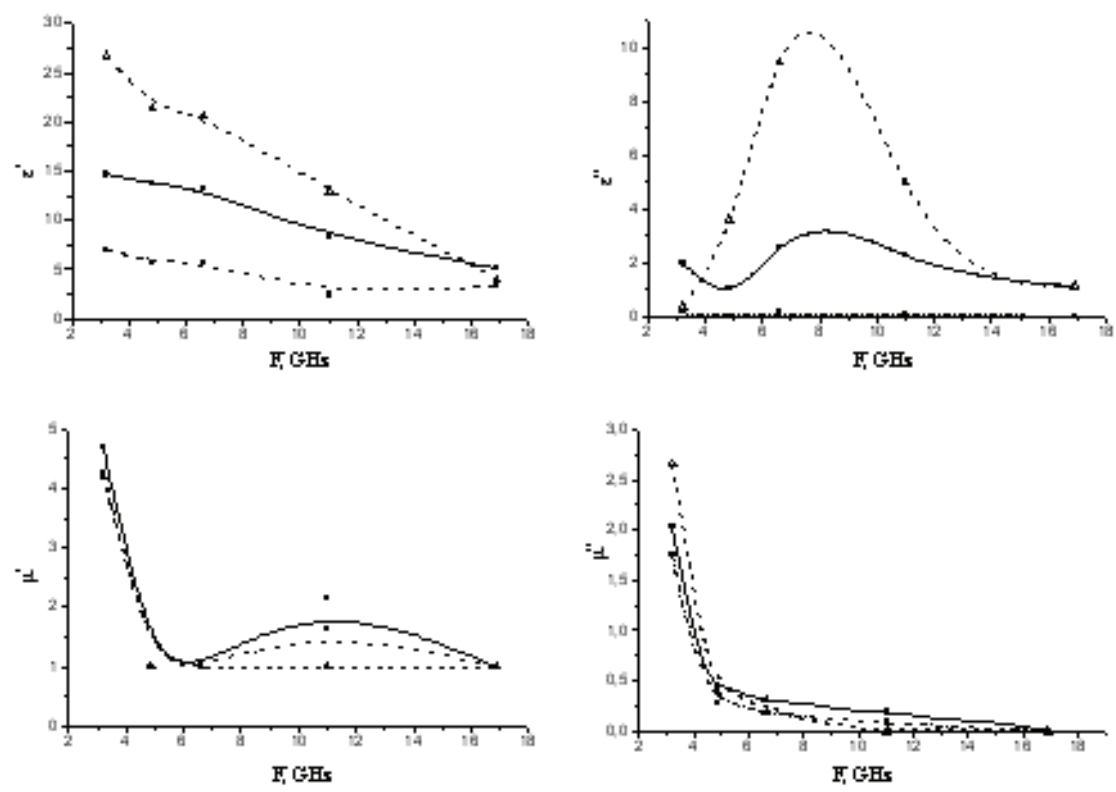

Fig. 7. Influence of the additional annealing in inert atmosphere and in air on properties of the composite with $63 \%$ wt. $\mathrm{Fe}_{3} \mathrm{O}_{4}: \longrightarrow$ initial sample; - $-\Delta-$ - sample annealed in inert atmosphere; - a -sample annealed in air

According to the percolation theory, dependencies of conductivity and dielectric permittivity of composites with disperse phase as functions of filler concentration can be described as (Efros \& Shklovskii, 1976):

$$
\begin{gathered}
\sigma \sim \sigma_{\mathrm{m}}\left(\mathrm{v}_{\mathrm{f}}^{*}-\mathrm{v}_{\mathrm{f}}\right)^{-\mathrm{q}} \\
\varepsilon^{\prime} \sim \varepsilon_{\mathrm{m}}\left(\mathrm{v}_{\mathrm{f}}^{*}-\mathrm{v}_{\mathrm{f}}\right)^{-\mathrm{q},} \quad \mathrm{v}_{\mathrm{f}}<\mathrm{v}_{\mathrm{f}}^{*},
\end{gathered}
$$

where $\sigma_{\mathrm{m}}$ is the specific conductivity of the polymer matrix;

$\varepsilon_{\mathrm{m}}$ is the dielectric permittivity of the polymer matrix;

$\mathrm{v}_{\mathrm{f}}$ is the volume concentration of the filler;

$\mathrm{V}_{\mathrm{f}}^{*}$ is the percolation threshold.

Therefore, conductivity and dielectric permittivity of a composite with a conducting filler are exponential functions, which provides means for explanation of $\varepsilon^{\prime}$ and $\varepsilon^{\prime \prime}$ dependencies as functions of nanoparticles concentration. 
As it follows from the results of studies of the influence of thermal treatment on $\varepsilon^{\prime}$ and $\varepsilon^{\prime \prime}$, these values are mainly determined by the inner structure of nanoparticles or ratio of phases they are comprised of, which can have a significant effect on concentrations of free and bound charges in them. Contribution of charge states on both the surface of nanoparticles and metal-polymer interface can be another important factor.

Magnetic losses in these materials as a function of frequency can be attributed to the resonance of domain borders in single-domain particles and natural ferromagnetic resonance..

\subsection{Electrophysical properties of composites containing CdS nanoparticles}

Nanocomposites based on semiconductor nanoparticles stabilized in LDPE matrix are of special practical interest (Ushakov et al., 2006; Ponomareva et al., 2007, a; Kul'batskii et al., 2009; Radchenko et al., 2009). Electrophysical properties of a series of such materials containing $20 \% \mathrm{wt}$. CdS nanoparticles have been studied. The samples differed in average sizes of nanoparticles which were in the range from 4.9 to $19.5 \mathrm{~nm}$.

Electric conductivity values $(\sigma)$ of the samples measured at $300 \ldots 420 \mathrm{~K}$ were in the range of $0.01 \div 0.54 \mu \mathrm{S}$. A dependence of $\sigma$ as a function of reciprocal temperature during heating and cooling of a nanocomposite with CdS nanoparticles $4.9 \mathrm{~nm}$ in size is depicted in fig. 8 (the arrows indicate the process direction). A small hysteresis of $\sigma$ is observed during cooling, which is obviously connected to reorganization of the dielectric matrix material. The temperature hysteresis of electric conductivity is a new property of the nanocomposite medium. Also, two dramatic changes of conductivity are observed during heating at $c a .75$ and $95^{\circ} \mathrm{C}$. They can be probably attributed to a change of energy of charge carriers, which enables the latter to overcome potential barriers in the nanocomposite material.

Fig. 9 depicts a dependence of the real part of dielectric permittivity $\varepsilon$ as a function of temperature during heating and cooling (curve 1). The permittivity value increases during heating. Interestingly, this process continues during cooling after the temperature maximum has been reached. As a result, the value of $\varepsilon$ changes after the heating-cooling loop and doesn't change for some time (for at least 7 days). If the heating-cooling cycle is repeated, capacitance of the nanocomposite medium will increase, but this time the change will only be $10-20 \%$ of that after the first loop. The hysteresis becomes hardly observable starting from the $3^{\text {rd }}$ or $4^{\text {th }}$ loop. This behaviour of the composite material is obviously connected to the thermally stimulated process of the dielectric matrix structure rearrangement and, as a result, emerging of metastable states of the medium. The same dependence for the "empty" LDPE is depicted by curve 2 in fig. 9. In general, the behaviuor of the dependence is almost the same as in case of the metal-polymer nanocomposite; the only prominent difference is the much smaller (at least, 2 times smaller) temperature susceptibility of dielectric permittivity of LDPE. Therefore, impregnation of nanoparticles into a polymer matrix makes dielectric permittivity of the resulting material more susceptible to temperature changes, retaining the nature of its dependence as a function of temperature, in general. Permittivity $\varepsilon$ of nanocomposites based on LDPE with $20 \%$ wt. CdS nanoparticles is $5.60 \pm 0.32$ at $35^{\circ} \mathrm{C}$.

Fig. 10 depicts temperature dependencies of the relative value of dielectric permittivity of nanocomposite samples with $20 \%$ wt. CdS which differ in average sizes of the nanoparticles. Curves 1, 2, and 3 in fig. 10 correspond to the average sizes of $4.9,5.6$, and $6.2 \mathrm{~nm}$, respectively. As it follows from the dependencies acquired, size of nanoparticles has little effect on dependencies of relative permittivity as a function of temperature during cooling. 
However, a prominent effect is observed during heating. These dependencies are congruent for all the studied materials up to $50^{\circ} \mathrm{C}$. As temperature rises further, the growth rate of susceptibility to temperature becomes higher in case of smaller particles. It's worthwhile to note that size of nanoparticles has almost no effect on the relative change of dielectric permittivity during heating and cooling.

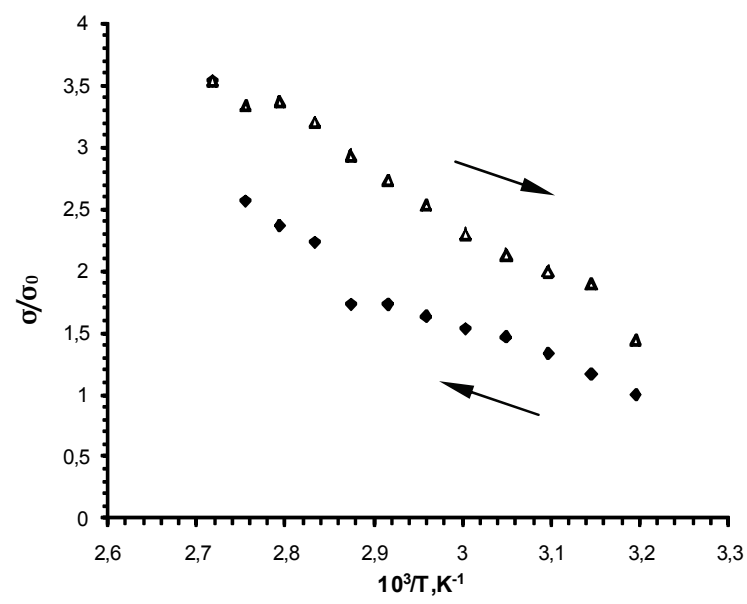

Fig. 8. Conductivity of a nanocomposite with $20 \%$ wt. CdS in LDPE as a function of reciprocal temperature

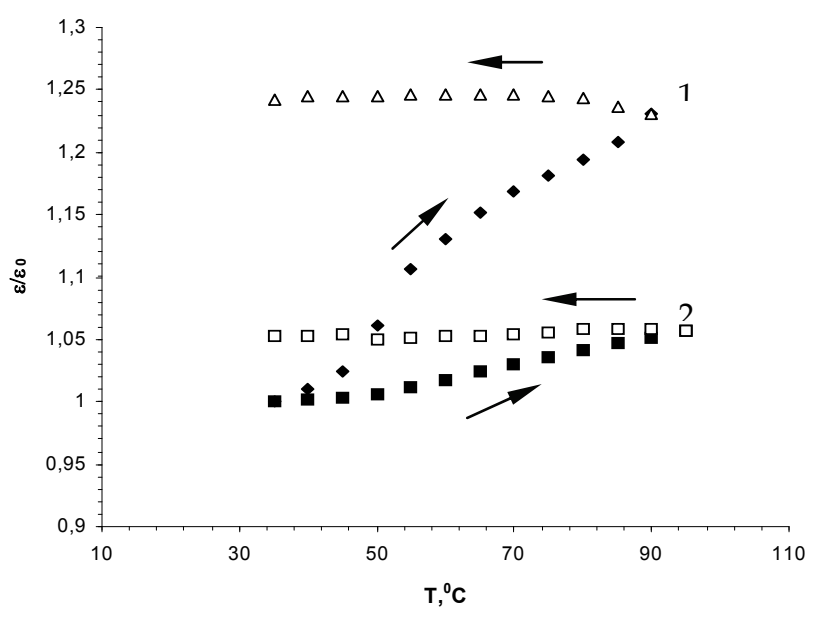

Fig. 9. The real part of dielectric permittivity as a function of temperature measured for: 1 . nanocomposite comprised of LDPE and $20 \%$ wt. CdS nanoparticles; 2. - LDPE 


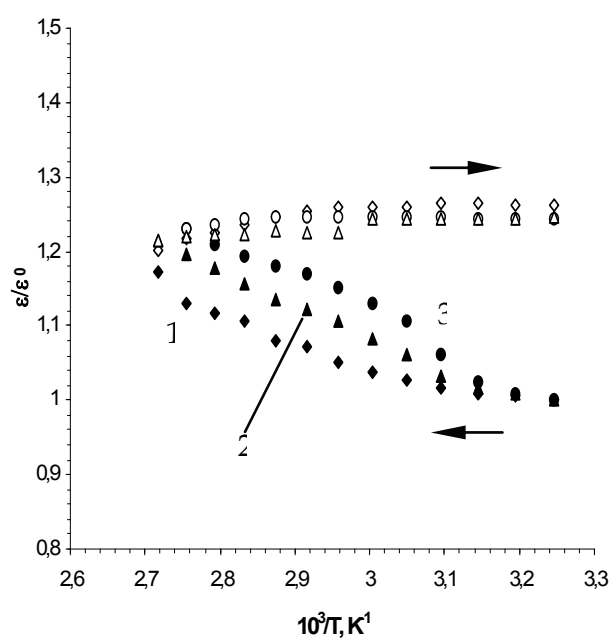

Fig. 10. Relative dielectric permittivity values as functions of temperature measured for nanocomposites with $20 \% \mathrm{wt}$. CdS nanoparticles in LDPE with the average size of nanoparticles equal to: 1) $4.9 \mathrm{~nm}$; 2) $5.6 \mathrm{~nm}$; 3) $6.2 \mathrm{~nm}$

Changes of dielectric loss factor induced by heating and cooling have been estimated. The relative change of dielectric loss factor after the whole cycle was found to be 1.79 . The value of dielectric loss factor of the samples studied was 0.0088 at $35^{\circ} \mathrm{C}$ (which was the initial temperature).

Fig. 11 depicts dependences of dielectric relaxation time as functions of temperature measured during the heating-cooling process. Heating leads to a monotonous growth of dielectric relaxation time. Also, a small temperature hysteresis of the relaxation time values is observed.

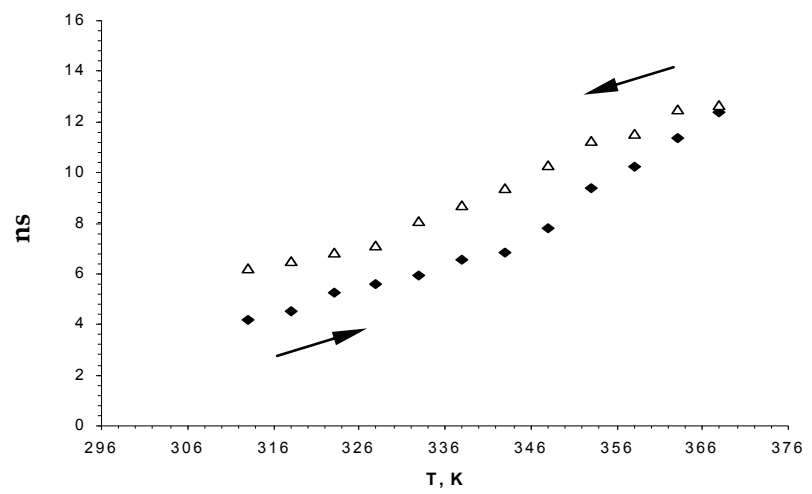

Fig. 11. Dielectric relaxation times of samples comprised of $20 \%$ wt. CdS in LDPE as functions of temperature 
Dielectric relaxation times did not exceed 20 ns.

Fig. 12 depicts relative activation energy of relaxation processes as a function of temperature during heating and cooling of the sample containing $20 \%$ wt. Co. A common feature of the dependences measured is the growth of activation energy during heating and its decrease during cooling, which corresponds to a change of charge carrier energy with temperature changing and, therefore, a shift of Fermi level within the band gap of the material. It may result in release of trapped charges, therefore changing dielectric peoperties of a medium. It's worthwhile to note that this dependence is almost linear. The range of dielectric relaxation activation energy change was found to be $10-30 \mathrm{~kJ} /(\mathrm{K} \cdot \mathrm{mol})$.

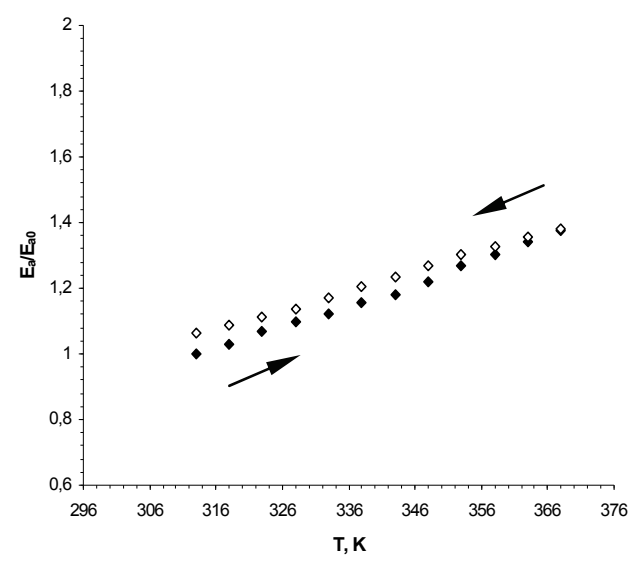

Fig. 12. Relative activation energy of dielectric relaxation processes in samples comprised of $20 \%$ wt. CdS nanoparticles in LDPE as a function of temperature

Therefore, the measured kinetic and energy parameters of temperature dependences in composite nanomaterials based on LDPE containing 20\% wt. CdS nanoparticles allow qualitatively describe energy spectra of such materials. In our assumption, they are a set of mini-zones in the band gap near the top of the valent zone. In this case, the behaviour of dependencies of the parameters of the composites studied as functions of temperature can be attributed to charge carrier transitions between those mini-zones (Ul'zutuev et al., 2009). Further investigations revealed that such hysteresis behaviour of dielectric permittivity, dielectric losses, and time of dielectric relaxation as functions of temperature are also inherent to composite nanomaterials comprised of ceria nanoparticles in LDPE.

\subsection{Electrophysical properties of composites containing $\mathbf{C u} @ \mathrm{Cu}_{2} \mathrm{O}$ nanoparticles}

Fig. 13 depicts dependences of relative values of specific conductivity $\left(G_{x} / G_{0}\right.$, curve 1$)$, permittivity $\left(\varepsilon_{x} / \varepsilon_{0}\right.$, curve 2$)$, and dielectric loss coefficient (curve 3 ) as functions of nanoparticle concentration recorded at $1 \mathrm{MHz}$ and $\mathrm{T}=300 \mathrm{~K}$ for samples comprised of $\mathrm{Cu} @ \mathrm{Cu}_{2} \mathrm{O}$ nanoparticles in LDPE which have different concentrations of nanoparticles. The initial values of conductivity, permittivity, and dielectric loss coefficient of the $\mathrm{Cu} @ \mathrm{Cu}_{2} \mathrm{O} / \mathrm{LDPE}$ sample with low nanoparticles concentration $(\mathrm{x}<10 \% \mathrm{wt}$ ) were $G_{b}=1.1 \mu \mathrm{S} / \mathrm{m}, \varepsilon_{b}=2.5$, and $\tan d_{b}=0.015$, respectively. As concentration of nanoparticles 
grows, dielectric permittivity increases up to 6 times, dielectric losses at $1 \mathrm{MHz}$ increase up to 3 times, and specific conductivity becomes almost up to 1.5 times higher at 30 mass. $\%$ nanoparticles. However, conductivity decreases as concentration of nanoparticles rises from $10 \%$ to $20 \%$ wt.

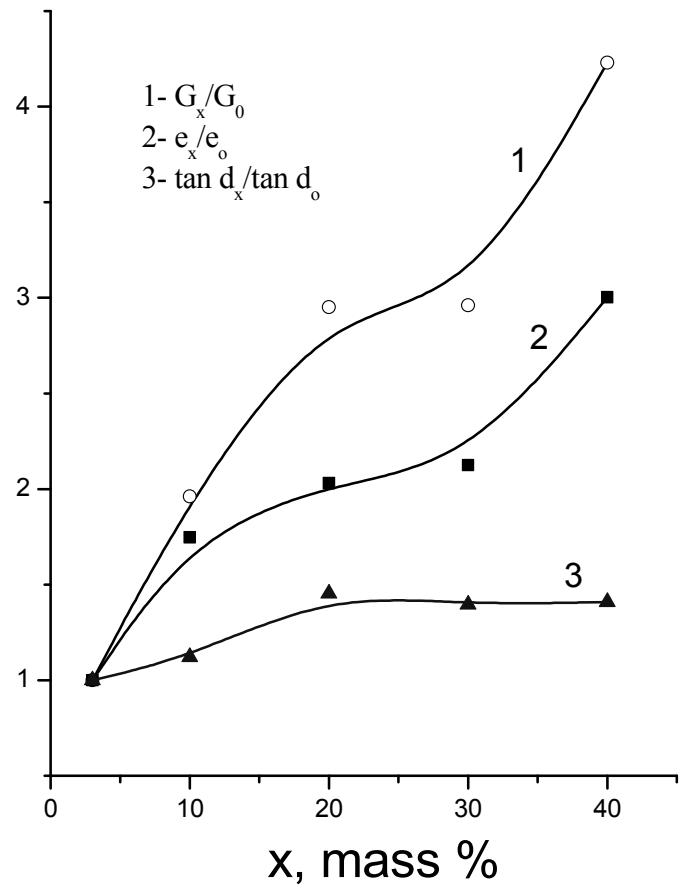

Fig. 13. Relative values of specific conductivity $\left(G_{x} / G_{0}\right.$, curve 1$)$, dielectric permittivity $\left(\varepsilon / \varepsilon_{0}\right.$, curve 2), and dielectric loss coefficient (curve 3) as functions of nanoparticles concentration (x, wt.\%) in composites comprised of $\mathrm{Cu} @ \mathrm{Cu}_{2} \mathrm{O}$ nanoparticles in LDPE

Studies of applications of $\mathrm{Cu}$-containing nanocomposites in waveguide and resonator SHF devices as dielectric insertions revealed that such materials are prospective for controlling resonance frequencies of induced waves and field structure in such systems.

Logarithmic dependencies of current at $1 \mathrm{MHz}$ as functions of reciprocal temperature measured for samples with 20, 25, and 30\% wt. $\mathrm{Cu} @ \mathrm{Cu}_{2} \mathrm{O}$ in LDPE are given in fig. 14 (curves 1, 2, and 3, respectively).

Logarithmic dependences of current as functions of reciprocal temperature measured at $1 \mathrm{MHz}$ for nanocomposites with different concentrations of copper-containing nanoparticles are depicted in fig. 14.

The current maximum (point A) shifts to higher temperatures as nanoparticles concentration grows. Different signs of derivatives of these functions are obviously due to different mechanisms of charge carrier dissipation in the nanocomposites. 


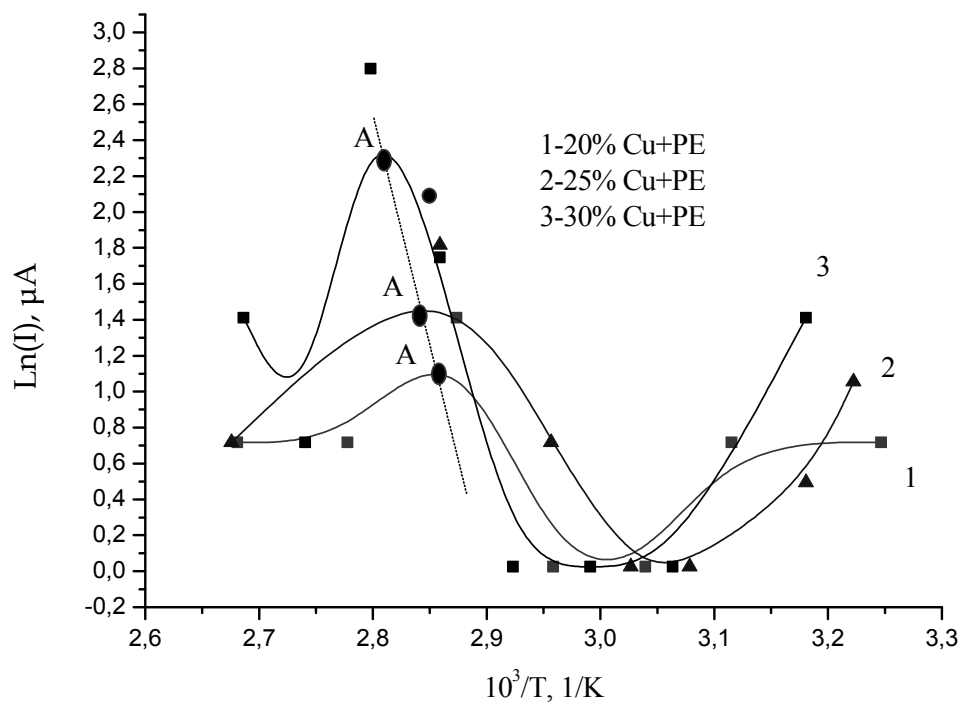

Fig. 14. Logarithmic dependences of current as functions of reciprocal temperature measured at $1 \mathrm{MHz}$ for nanocomposites with different concentrations of copper-containing nanoparticles. Point A corresponds to a current maximum

\subsection{Optical properties of the $\mathrm{CeO}_{2}$ nanocomposites}

The main measured values were the coefficient of reflection $R=I_{r} / I_{0}$ and coefficient of transmission $T=I_{o u t} / I_{o}$, where $I_{r}, I_{o u t}$, and $I_{o}$ are the intensities of the reflected, transmitted and initial optical signals, respectively. Calculations of all the main spectral and optical properties of the samples were based on the measured dependencies $R(\lambda)$ and $T(\lambda)$. The "Kubelk-Munk" two-stream model was used as the experimental model; it has been successfully applied for optical investigations of biological environments.

The spectral dependencies of the optical absorption coefficient of the composite nanomaterials with the nanoparticle sizes ranging from $3.3 \mathrm{~nm}$ to $4.9 \mathrm{~nm}$ are shown in Figure 15. The measured dependences have absorption maxima shifted $15 \mathrm{~nm}$ far from each other. The maximum absorption corresponding to the larger nanoparticles is shifted towards the short wavelength region. It should be noted that the edge of the fundamental optical absorption of the low density polyethylene matrix is located in the short wavelength region $(\mathrm{nm})$. It is known that the optical properties of composite materials mainly depend on the properties of excitons and polaritons. Excitons and polaritons are induced within the nanoparticles and at the nanoparticle-matrix boundaries (the Maxwell Wagner effect).

New aspects of exciton-radiation interaction are discussed from the viewpoint of microscopic nonlocal optical sponse developed for the study of nano-structures materials are reviewed in (Gorobinskii et al., 2007; Ushakov et al., 2008). Localization of excitons within the nanoparticles dramatically increases the binding energy (up to 20-30 meV) and the exciton oscillator strength. The increase of the binding energy is due to the decrease of the distance between electrons and holes which leads to intensification of the Coulomb interaction. Applying a matrix with small permittivity may increase the binding energy by an order of magnitude (up to $0.2-0.3 \mathrm{eV}$ ). The dielectric amplification caused by the 
Coulomb energy concentration showed a large difference in the dielectric constants of nanoparticles in this matrix system. The measurement of the dielectric constant of the $10 \%$ wt. $\mathrm{CeO}_{2}-\mathrm{PE}$ composite material showed its effective value to be $3.8 \pm 0.1$ at a frequency of $1 \mathrm{MHz}$. The dielectric constant of LDPE is equal to 2.2 \pm 0.1 . The collected optical absorption spectra (Figure 15) correspond to the exciton spectra of nanoparticles of different sizes. The coefficient of optical absorption $K$ for the exciton transitions is determined by the following equitation [27]:

$$
K=A \frac{8}{\pi^{2}}\left(\frac{\overline{\dot{a}}}{a_{e x}}\right)^{3}\left(\frac{\hbar^{2} \pi^{2}}{M \bar{a}^{2}}\right)^{-1} \sum_{n} \frac{1}{n^{2}} \delta\left(\Delta+E_{e x}-\frac{\hbar^{2} \pi^{2} n^{2}}{2 M \bar{a}^{2}}\right)
$$

where $\mathrm{A}$ is the variable proportional to the square of the modulus of the matrix dipole moment calculated based on the Blokhov functions; $\bar{a}$ is the average size of nanoparticles; $a_{e x}$ is the exciton radius; $M=m_{e}+m_{h}$ is the total mass of an exciton ( $m_{e}$ is the mass of an electron, $m_{h}$ is the mass of a hole); $\hbar$ is the reduced Planck constant; $n$ is the number of electron levels ( $n=1$ is the lowest level); $E_{e x}$ is the exciton energy; $\Delta=\hbar \omega-E_{g} ; \hbar \omega$ is the photon energy; $E_{g}$ is the band-gap energy.

According to Equation (1), the shift of the absorption maximum for the highest oscillation strength $(n=1)$ depends on the value of $M \bar{a}^{2}$; i.e., it depends on the mass and average radius of an exciton. In the case of ensembles of nanoparticles with the same average size, a decrease in their size without changing their mass shifts the absorption maximum towards the short-wave region of the spectrum (the so-called "blue shift"). In our case, the inverse situation occurred: the absorption maximum for the $\mathrm{CeO}_{2}$ nanoparticles obtained from $\left(\mathrm{Et}_{4} \mathrm{~N}\right)_{2} \mathrm{Ce}\left(\mathrm{NO}_{3}\right)_{6}$ with the size of $4.9 \mathrm{~nm}$ is shifted by $15 \mathrm{~nm}$ towards higher frequencies compared to the $\mathrm{CeO}_{2}$ nanoparticles with the size of $3.3 \mathrm{~nm}$ obtained from $\left(\mathrm{NH}_{4}\right)_{2} \mathrm{Ce}\left(\mathrm{NO}_{3}\right)_{6}$. Apparently, the shift can be explained by the fact that the mass of an exciton is noticeably lower for larger nanoparticles than for smaller ones. Hence, the multiplication product of the mass of an exciton by its radius gives a lower value for larger particles and results in a longer shift than for small nanoparticles. The widening of the optical absorption spectra at wavelengths longer than $550 \mathrm{~nm}$ observed for the nanoparticles with different average sizes (curves 1 and 2; Figure 15) is caused by the statistical size distribution of the particles.

The dispersion characteristics of the $10 \%$ wt. $\mathrm{CeO}_{2}-\mathrm{LDPE}$ composite are shown in Figure 16. The index of refraction is noticeably higher for the smaller nanoparticles than for the larger ones. The exception is the point "a" $(\lambda=623 \mathrm{~nm})$. The dispersion curve is very steep in the $400-500 \mathrm{~nm}$ region for the smaller nanoparticles, and this steepness is not observed for the larger nanoparticles.

The mean values of the index of refraction $\left\langle n_{0}\right\rangle$ and the index of adsorption $\langle k\rangle$ in the complex index of refraction $\left(n=n_{0}-j k\right)$ of the composite medium were calculated based on spectral data. For the pure polyethylene, these values are $\left\langle n_{0}\right\rangle=1.5$, and $\langle k\rangle=1.166 \cdot 10^{-5}$.

The dependencies of the index of refraction as subject to the nanoparticle size are shown in Figure 17 (a). As mentioned previously, composite nanomaterials are the media with the complex index of refraction $n=n_{0}-j k$; where $n_{0}$ is the index of refraction, and $k$ is the index of absorption.

The increase in the index of refraction with the decrease of the nanoparticle size can be explained by the growth of the polarization of the electric dipoles at the nanoparticle-matrix boundary (the Maxwell-Wagner effect) (see Figure 17). 
The optical absorption, which is determined by the absorbing volume and the size of nanoparticles, increased along with an increase in concentration, in which case, the average value of the optical absorption coefficient should grow along with the size of the nanoparticles. Such behavior of both the optical refraction and absorption indexes is depicted in Figures 17 (b, c).

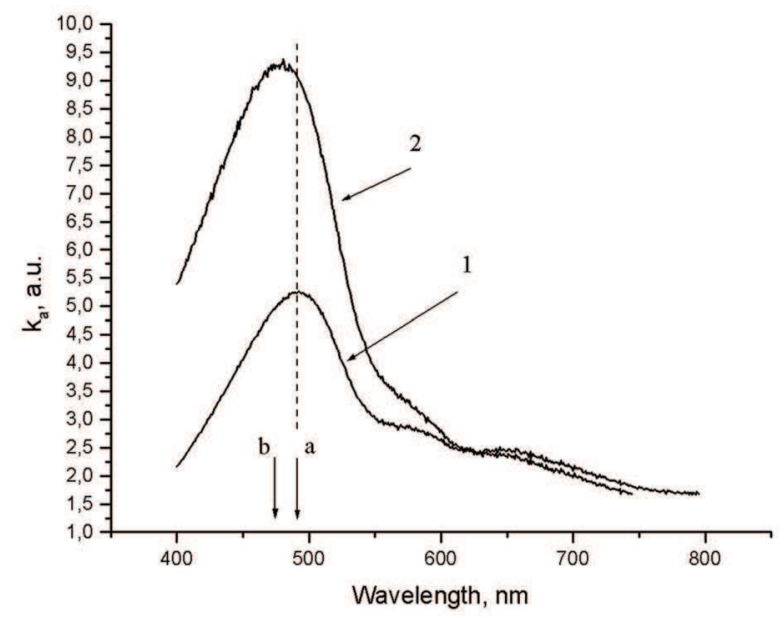

Fig. 15. Optical absorption in the $10 \%$ wt. $\mathrm{CeO}_{2}$-LDPE composite nanomaterial: line 1 corresponds to the $\mathrm{CeO}_{2}$ nanoparticles with the size of $3.3 \mathrm{~nm}$; line 2 corresponds to the $\mathrm{CeO}_{2}$ nanoparticles with the size of $4.9 \mathrm{~nm}$. The points " $\mathrm{a}$ " and " $\mathrm{b}$ " are the maxima of the curves at 492 and $477 \mathrm{~nm}$, respectively

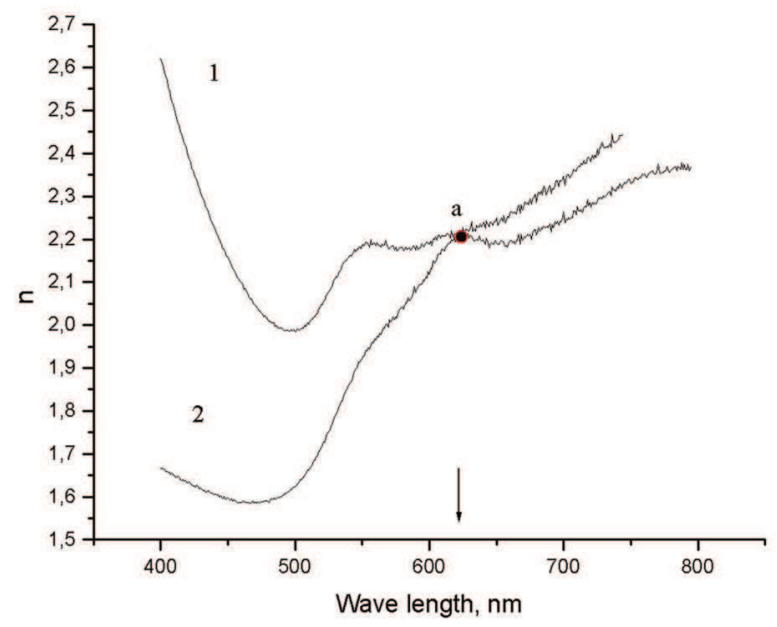

Fig. 16. The dispersion characteristics of the $\mathrm{CeO}_{2}$-LDPE nanocomposite containing $10 \% \mathrm{wt}$. $\mathrm{CeO}_{2}$ nanoparticles with different sizes. Curve 1: the average size of nanoparticles is $3.3 \mathrm{~nm}$; curve 2: the average size of nanoparticles is $4.9 \mathrm{~nm}$ 

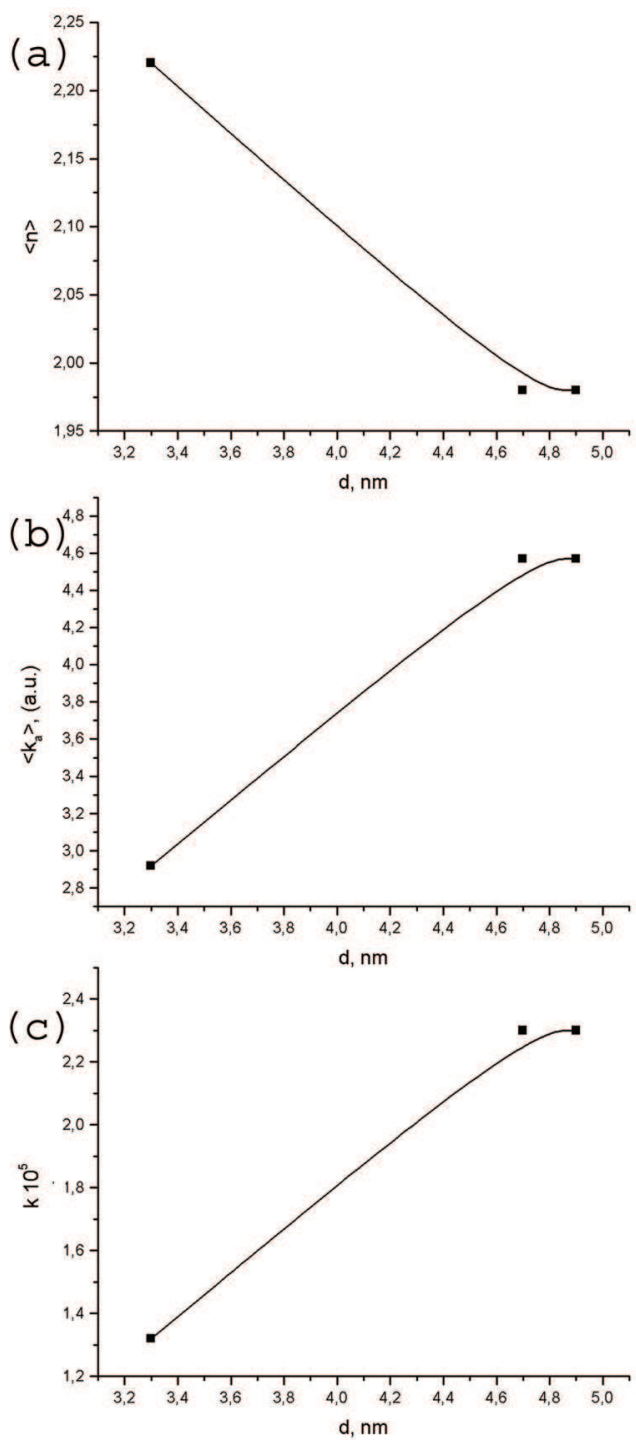

Fig. 17. Dependencies of the index of refraction (a), index of optical absorption (b), and absorption coefficient of the materials with nanoparticles having different average sizes (c) Interesting optical properties of composites based on $\mathrm{ZnO}, \mathrm{CdS}$, and $\mathrm{CuO}$ nanoparticles were described elsewhere (Ushakov et al., 2006; Ponomareva et al., 2007, b; Yurkov et al., 2009; Kul'batskii et al., 2009). 


\section{Conclusion}

1. Electrophysical properties of metal-polymer nanocomposites comprised of iron-, cobalt, copper-containing or CdS nanoparticles embedded in low density polyethylene have been studied.

2. Measurements revealed that dielectric permittivity and electromagnetic radiation absorption of a nanostructured material grow as concentration of nanoparticles in the material increases.

3. Variation of size and concentration of nanoparticles has been found to change electrophysical properties of composite materials, namely: dielectric permittivity, volume resistance.

4. Microwave measurements characterize the samples studied as materials with steady absorption and permittivity in a wide band within the frequency range studied.

5. Dependences of dielectric permittivity, dielectric losses, and dielectric relaxation times of composite materials comprised of $\mathrm{CeO}_{2}$ or $\mathrm{CdS}$ nanoparticles impregnated in LDPE have a hysteresis nature as functions of temperature.

6. Composites undergo additional polarization after cooling, and their dielectric permittivity increases by $\Delta \varepsilon$ (this value depends on nanoparticles size). $\Delta \varepsilon$ equals 1.31.4 for small nanoparticles ( $\sim \mathrm{nm})$ and lowers as nanoparticles size grows.

The composite medium changes its state stepwise during heating. The transition occurs at lower temperatures in case of smaller nanoparticles and longer times of dielectric relaxation, which is obvious because smaller nanoparticles are more chemically active. The higher the activation energy, the more rapid are the processes of dipole orientation in external magnetic field.

\section{References}

Brosseau, C.; Quéffélec, P. \& Talbot, P. (2001). Microwave characterization of filled polymers. J. Appl. Phys. Vol. 89, No. 8, p. 4532-4540, ISSN 0021-8979.

Efros, A.L. \& Shklovskii B.I. (1976). Critical behaviour of conductivity and dielectric constant near the metal-non-metal transition threshold. Physica status solidi (b). Vol. 76, Is. 2, p. 475-485, ISSN 0370-1972.

Elkin, P.K. \& Yurkov, G.Yu. (2009). Ultrasound-provided synthesis of cobalt-containing nanoparticles. In: Physics, chemistry and application of nanostructures , Borisenko, V.E.; Gaponenko, S.V.; Gurin, V.S. (Ed.), p. 369-372, World Scientific, ISBN 978-981-428035-8, Singapore.

a) Fionov, A.S.; Yurkov, G.Yu.; Kolesov, V.V.; Taratanov, N.A. \& Petrova, N.G. (2008). Poglotiteli elektromagnitnyh voln na osnove zhelezo- i kobal'tsoderjaschih nanochastic. Perspektivnye materialy. No. 6 (1), p. 192-196.

b) Fionov, A.S.; Yurkov, G.Yu.; Potapov, A.A.; Kolesov, V.V. \& Taratanov, N.A. (2008). Perspektivnye nanostrukturirovannye polimernye kompozicionnye materialy dlya fizicheskih issledovanii ih metodami fraktal'nogo analiza. Nelineinyi mir. Vol. 6, No. 1, p. 37-41.

Gangopadhyay, R. \& De, A. (2000). Conducting Polymer Nanocomposites: A Brief Overview. Chem. Mater. Vol. 12, No. 3, p. 608-622, ISSN 0897-4756. 
Gleiter, H.; Weissmüller, J.; Wollersheim, O. \& Würschum, R. (2001). Nanocrystalline materials: a way to solids with tunable electronic structures and properties? Acta Materialia. Vol. 49, No. 4, p. 737-745, ISSN 1359-6454.

Gorobinskii, L.V.; Yurkov, G.Yu. \& Baranov, D.A. (2007). Production of high porosity nanoparticles of cerium oxide in clay. Microporous and Mesoporous Materials. Vol. 100, No. 1-3, p. 134-138, ISSN 1387-1811.

Gubin S.P. (2000). Chto takoe nanochastica? Tendencii razvitiya nanohimii i nanotehnologii. Rossiiskii himicheskii jurnal. Vol. 44. No. 6, p. 23-31, ISSN 0373-0247.

Gubin, S.P.; Spichkin, Yu.I.; Yurkov, G.Yu. \& Tishin, A.M. (2002). Nanomaterials for high density magnetic data storage. Russian Journal of Inorganic Chemistry. Vol. 47, Suppl. 1, p. 32-67, ISSN 0036-0236.

Gubin, S.P.; Spichkin, Yu.I.; Koksharov, Yu.A.; Yurkov, G.Yu.; Kozinkin, A.V.; Nedoseikina, T.I.; Vlasenko, V.G.; Korobov, M.S. \& Tishin, A.M. (2003). Magnetic and structural properties of Co nanoparticles in polymeric matrix. Journal of Magnetism and Magnetic Materials. Vol. 265, No. 2, p. 234-242, ISSN 0304-8853.

a) Gubin, S.P.; Koksharov, Yu.A.; Khomutov, G.B. \& Yurkov G.Yu. (2005). Magnetic nanoparticles: preparation, structure and properties. Russian Chemical Reviews. Vol. 74, No. 6, p. 489-520, ISSN 0036-021X.

b) Gubin, S.P.; Yurkov, G.Yu. \& Kosobudsky, I.D. (2005). Nanomaterials based on metalcontaining nanoparticles in polyethylene and other carbon-chain polymers. International Journal of Materials and Product Technology. Vol. 23, No. 1-2, p. 2-25, ISSN 0268-1900.

Gudoshnikov, S.; Liubimov, B.; Matveets, L.; Ranchinski, M.; Usov, N.; Gubin, S.; Yurkov, G.; Snigirev, O. \& Volkov. I. (2003) Magnetic properties of Fe-based nanoparticle assembly. Journal of Magnetism and Magnetic Materials. Vol. 258-259, p. 54-56, ISSN 0304-8853.

Hong, J.I.; Schadler, L.S. \& Siegel, R.W. (2003). Rescaled electrical properties of ZnO'low density polyethylene nanocomposites. Appl. Phys. Lett. Vol. 82, No. 12, p. 1956-1958, ISSN 0003-6951.

Hong, J.I.; Winberg, P.; Schadler, L.S. \& Siegel, R.W. (2005). Dielectric properties of zinc oxide/low density polyethylene nanocomposites. Materials Letters. Vol. 59, No. 4, p. 473-476, ISSN 0167-577X.

Hyeon T. (2003). Chemical synthesis of magnetic nanoparticles. Chem. Commun. p. 927-934, ISSN 1364-548X.

Kawasumi, M.; Hasegawa, N.; Kato, M.; Usuki, A. \& Okada, A. (1997). Preparation and Mechanical Properties of Polypropylene-Clay Hybrids. Macromolecules. Vol. 30, No. 20, p. 6333-6338, ISSN 0024-9297.

Korobov, M.S.; Yurkov, G.Yu.; Kozinkin, A.V.; Koksharov, Yu.A.; Pirog, I.V.; Zubkov, S.V.; Kitaev, V.V.; Sarychev, D.A.; Buznik, V.M.; Tsvetnikov, A.K. \& Gubin S.P. (2004). Metal-Containing Poly(tetrafluoroethylene): A Novel Material. Inorganic Materials. Vol. 40, No. 1, p. 26-35, ISSN 0020-1685.

Kosobudsky, I.D. \& Yurkov G.Yu. (2000). Metall-containing nanoparticles in polymeric matrix.: II. Syntheses, physical and chemical properties. Application. Izvestia vysshikh uchebnykh zavedeniy. Khimia I khimicheskay tekhnologia. No. 5, p. 3-19.

Kul'batskii, D.M.; Ushakov, N.M.; Yurkov, G.Yu. \& Podvigalkin V.Ya. (2009). Issledovanie opticheskikh kharakteristik kompozitnykh materialov na osnove nanochastits 
sul'fida kadmiya, stabilizirovannykh v matritse polietilena vysokogo davleniya. Optika i spektroskopiya. Vol. 106, No. 5, p. 780-784.

Lin, X.-M. \& Samia, A.C.S. (2006). Synthesis, assembly and physical properties of magnetic nanoparticles. Journal of Magnetism and Magnetic Materials. Vol. 305, p. 100-109, ISSN 0304-8853.

Pomogailo, A.D.; Rozenberg, A.S. \& Uflyand, I.E. (2004). Nanochasticy metallov v polimerah. Himiya, ISBN 5-7245-1107-X, Moskva.

a) Ponomareva, K.Yu.; Kosobudsky, I.D.; Tret'yachenko, E.V. \& Yurkov, G.Yu. (2007). Synthesis and Properties of CdS Nanoparticles in a Polyethylene Matrix. Inorganic Materials. Vol. 43, No. 11, p. 1160-1166, ISSN 0020-1685.

b) Ponomareva, K.Yu. Kosobudskii, I.D.; Yurkov, G.Yu. \& Kochubei, V.I. (2007). Issledovanie struktury nanochastic sul'fidov kadmiya i cinka, sintezirovannyh $\mathrm{v}$ matrice polietilena vysokogo davleniya. Vestnik Saratovskogo gosudarstvennogo tehnicheskogo universiteta. No. 2 (24), Is. 1, p. 60-65.

Popkov, O.V.; Yurkov, G.Yu. \& Fionov A.S. (2009). Stabilization of nanoparticles on the surface of detonation nanodiamond. In: Physics, chemistry and application of nanostructures, Borisenko, V.E.; Gaponenko, S.V.; Gurin, V.S. (Ed.), p. 369-372, World Scientific, ISBN 978-981-270-599-0, Singapore.

Radchenko, M.V.; Lashkarev, G.V.; Sichkovskyi, V.I.; Arshakuni, A.A.; Gubin, S.P.; Yuhymchuk, V.O.; Domukhovski, V.; Story, T.; Piryatinskii, Yu.P. \& Yurkov G.Yu. (2009). Nanomaterials Based on CdS Nanoparticles in Polyethylene Matrix. Inorganic Materials. Vol. 45, No. 5, p. 468-473, ISSN 0020-1685.

Scomski, R. (2003). Nanomagnetics. Journal of Physics: Condensed Matter. Vol. 15, p. R841R896, ISSN 0953-8984.

Siegel, R. W. (1993). Nanostructured materials -mind over matter. Nanostruct. Mater. Vol. 3, No 1-6, p. 1-18, ISSN 0965-9773.

a) Taratanov, N.A.; Yurkov, G.Yu.; Fionov, A.S.; Koksharov, Yu.A.; Popkov, O.V. \& Kolesov, V.V. (2009). Creation and Physical Properties of the Molybdenum-Containing Polyethylene-Based Nanomaterials. Journal of Communications Technology and Electronics. Vol. 54, No. 8, p. 937-946, ISSN 1064-2269.

b) Taratanov, N.A.; Yurkov, G.Yu.; Fionov, A.S.; Boimuratov, F.T.; Abdurahmanov, U. \& Kosobudskii, I.D. (2009). Svinecsoderjaschie kompozicionnye nanomaterialy na osnove polietilena. Izvestiya vysshih uchebnyh zavedenii. Himiya $i$ himicheskaya tehnologiya. Vol. 52, No. 7, p. 72-75.

Taratanov, N.A.; Yurkov, G.Yu. \& Kosobudskii I.D (2010). Sintez reniisoderjaschih nanochastic na poverhnosti mikrogranul politetraftoretilena. Vestnik Saratovskogo gosudarstvennogo tehnicheskogo universiteta. No. 1 (44), p. 95-101.

Ul'zutuev, A.N.; Ushakov, N.M.; Yurkov, G.Yu. \& Kosobudskii, I.D. (2009). Teplovoi gisterezis dielektricheskih svoistv $\mathrm{v}$ kompozitah na osnove nanochastic oksidov i sul'fidov perehodnyh metallov v matrice polietilena vysokogo davleniya. Pis'ma v jurnal tehnicheskoi fiziki. Vol. 35, No. 10, p. 80-86.

Ushakov, N.M.; Kosobudskii, I.D.; Yurkov, G.Yu.; Gubin, S.P.; Zapsis, K.V.; Kochubei, V.I. \& Ul'zutuev, A.N. (2005). Novye kompozicionnye nanomaterialy s upravlyaemymi svoistvami dlya radiotehniki i elektroniki. Radiotehnika. No. 10, p. 105-108.

Ushakov, N.M.; Yurkov, G.Yu.; Baranov, D.A.; Zapsis, K.V.; Zhuravleva, M.N.; Kochubey, V.I. \& Kosobudsky, I.D. (2006). Opticheskie i fotoluministsentnye svoistva 
kompozitnykh nanomaterialov na osnove nanochastits sul'fida kadmiya i polietilena vysokogo davleniya. Optika i spektroskopiya. Vol. 101, No. 2, p. 262-267.

Ushakov, N.M.; Yurkov, G.Yu.; Gorobinskii, L.V.; Popkov, O.V. \& Kosobudskii, I.D. (2008). Nanocomposites based on the cerium oxide nanoparticles and polyethylene matrix: syntheses and properties. Acta Materialia. 2008. Vol. 56, No. 10, p. 2336-2343, ISSN 1359-6454.

Volkov, A.N.; Yurkov, G.Yu.; Ovchenkov, E.A.; Koksharov, Y.A.; Popkov, O.V.; Ivicheva, S.N.; Matveev, V.V. \& Kargin Yu.F. (2010). Composite material based on $\mathrm{SiO}_{2}$ micro-granules and cobalt nanoparticles. Perspektionye materialy. No. 4, p. 56-59.

Wang, Y. \& Herron, N. (1991). Nanometer-sized semiconductor clusters: materials synthesis, quantum size effects, and photophysical properties. J. Phys. Chem. Vol. 95, No, 2, p. 525- 532, ISSN 1089-5639.

Xia, X.; Cai, S. \& Xie, C. (2006). Preparation, structure and thermal stability of Cu/LDPE nanocomposites. Materials Chemistry and Physics. Vol. 95, p. 122-129, ISSN 02540584 .

Yurkov, G.Yu.; Kozinkin, A.V.; Nedoseikina, T.I.; Shuvaev, A.T.; Vlasenko, V.G.; Gubin, S.P. \& Kosobudskii I.D. (2001). Copper Nanoparticles in a Polyethylene Matrix. Inorganic Materials. Vol. 37, No. 10, p. 997-1001, ISSN 0020-1685.

Yurkov, G.Yu.; Gubin, S.P.; Pankratov, D.A.; Koksharov, Yu.A.; Kozinkin, A.V.; Spichkin, Yu.I.; Nedoseikina, T.I.; Pirog, I.V. \& Vlasenko V.G. (2002). Iron(III) Oxide Nanoparticles in a Polyethylene Matrix. Inorganic Materials. Vol. 38, No. 2, p. 137145, ISSN 0020-1685.

Yurkov, G.Yu.; Baranov, D.A.; Dotsenko, I.P. \& Gubin, S.P. (2006). New magnetic materials based on cobalt and iron-containing nanoparticles. Composites part B: Engineering. Vol. 37, No. 6, p. 413-417, ISSN 1359-8368.

a) Yurkov, G.Yu.; Baranov, D.A. \& Gorobinskii, L.V. (2007). Synthesis of ceria oxide nanoparticles in polyethylene matrix, In: Physics, chemistry and application of nanostructures , Borisenko, V.E.; Gaponenko, S.V.; Gurin, V.S. (Ed.), p. 343-346, World Scientific, ISBN 978-981-270-599-0, Singapore.

b) Yurkov, G.Yu.; Fionov, A.S.; Koksharov, Yu.A.; Kolesov, V.V. \& Gubin S.P. (2007). Electrical and Magnetic Properties of Nanomaterials Containing Iron or Cobalt Nanoparticles. Inorganic Materials. Vol. 43, No. 8, p. 834-844, ISSN 0020-1685.

Yurkov, G.Yu.; Taratanov, N.A.; Kosobudskii, I.D. \& Naumenko, V.Yu. (2009). Med'soderjaschie kompozicionnye nanomaterialy. Vestnik Saratovskogo gosudarstvennogo tehnicheskogo universiteta. Vol. 39, No. 2. Is. 2, p. 37-43.

Zanetti, M.; Camino, G.; Reichert, P. \& Mülhaupt, R. (2001). Thermal Behaviour of Poly(propylene) Layered Silicate Nanocomposites. Macromol. Rapid Commun. Vol. 22, No. 3, p. 176-180, ISSN 1022-1336.

Zanetti, M. \& Costa, L. (2004). Preparation and combustion behaviour of polymer/layered silicate nanocomposites based upon PE and EVA. Polymer. Vol. 45, p. 4367-4373, ISSN 0032-3861. 


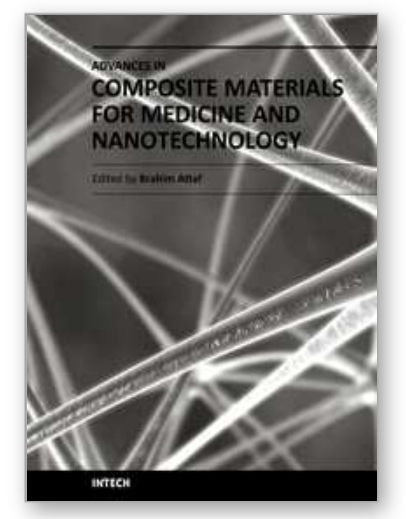

\section{Advances in Composite Materials for Medicine and Nanotechnology}

Edited by Dr. Brahim Attaf

ISBN 978-953-307-235-7

Hard cover, 648 pages

Publisher InTech

Published online 01, April, 2011

Published in print edition April, 2011

Due to their good mechanical characteristics in terms of stiffness and strength coupled with mass-saving advantage and other attractive physico-chemical properties, composite materials are successfully used in medicine and nanotechnology fields. To this end, the chapters composing the book have been divided into the following sections: medicine, dental and pharmaceutical applications; nanocomposites for energy efficiency; characterization and fabrication, all of which provide an invaluable overview of this fascinating subject area. The book presents, in addition, some studies carried out in orthopedic and stomatological applications and others aiming to design and produce new devices using the latest advances in nanotechnology. This wide variety of theoretical, numerical and experimental results can help specialists involved in these disciplines to enhance competitiveness and innovation.

\section{How to reference}

In order to correctly reference this scholarly work, feel free to copy and paste the following:

Gleb Yu. Yurkov, Alexandr S. Fionov, Oleg V. Popkov, Igor D. Kosobudskii, Nikolay A. Taratanov and Olga V. Potemkina (2011). Polymer Nanocomposites: Synthesis and Physical Properties, Advances in Composite Materials for Medicine and Nanotechnology, Dr. Brahim Attaf (Ed.), ISBN: 978-953-307-235-7, InTech, Available from: http://www.intechopen.com/books/advances-in-composite-materials-for-medicine-andnanotechnology/polymer-nanocomposites-synthesis-and-physical-properties

\section{INTECH}

open science | open minds

\section{InTech Europe}

University Campus STeP Ri

Slavka Krautzeka 83/A

51000 Rijeka, Croatia

Phone: +385 (51) 770447

Fax: +385 (51) 686166

www.intechopen.com

\section{InTech China}

Unit 405, Office Block, Hotel Equatorial Shanghai

No.65, Yan An Road (West), Shanghai, 200040, China

中国上海市延安西路65号上海国际贵都大饭店办公楼 405 单元

Phone: +86-21-62489820

Fax: $+86-21-62489821$ 
(C) 2011 The Author(s). Licensee IntechOpen. This chapter is distributed under the terms of the Creative Commons Attribution-NonCommercialShareAlike-3.0 License, which permits use, distribution and reproduction for non-commercial purposes, provided the original is properly cited and derivative works building on this content are distributed under the same license. 